\title{
The Correlation Between Septoria Leaf Spot and Stem Canker Resistance in Hybrid Poplar
}

Kelsey L. Dunnell, Department of Botany and Plant Pathology, Oregon State University, Corvallis 97331 and Department of Plant Pathology, North Dakota State University, Fargo 58108; and Jared M. LeBoldus, Forest Engineering and Resources Management and Department of Botany and Plant Pathology, Oregon State University, and Department of Plant Pathology, North Dakota State University

\begin{abstract}
Sphaerulina musiva is an important fungal pathogen that causes a leaf spot and stem canker disease of hybrid poplar. Stem cankers are widely regarded as the greatest threat to hybrid poplar plantations because of their ability to cause tree mortality; thus, the efforts of breeding programs have been focused on stem canker resistance. To explore the relationship between resistance to leaf spot and stem canker in Populus nigra $\times$ P. deltoides hybrids, two experiments were conducted. Initially, comparisons among leaves of different ages indicated that younger leaves were more susceptible to leaf

spot infection than older leaves. Correlations between leaf spot severity and stem canker severity for both individual leaves and all leaves averaged together indicated that, in 10 of 11 comparisons, there were no significant correlations. The lack of correlation suggests that deploying genotypes resistant to stem canker may not affect the pathogen population causing leaf spot disease. To our knowledge, this is the first study specifically designed to test the correlation between stem canker resistance and leaf spot resistance by inoculating whole trees with a spore suspension in a controlled environment
\end{abstract}

Short-rotation, intensively cultured plantations of hybrid poplar are used for wood and fiber production due to their fast growth rates and ease of clonal propagation (Bisoffi and Gullberg 1996; Dickmann 2001). However, hybrid poplar plantations in the eastern and central United States are affected by the fungal pathogen Sphaerulina musiva (Peck) Quaedvl., Verkley \& Crous (syn. = Septoria musiva Peck). This pathogen causes a leaf spot and stem canker disease of hybrid poplar (Bier 1939; Waterman 1954). Both leaf spots and stem cankers can affect the sustainability of hybrid poplar plantations. For example, Septoria leaf spot can result in a reduction in photosynthetic area leading to premature defoliation and reductions in yield (Krupinsky 1989; Ostry and McNabb 1985; Thompson 1941). Septoria stem canker can girdle the stem, killing trees or increasing the risk of stem breakage, potentially leading to plantation failure (Bier 1939; Ostry and McNabb 1985; Waterman 1954).

Outbreaks of this disease begin in the spring, when primary inoculum (ascospores produced in perithecia on leaf litter) are released (Bier 1939). Ascospore production peaks in early spring as buds swell, infecting newly emerging leaves and shoots (Luley and McNabb 1989; Ostry 1987). At 3 to 4 weeks following infection, lesions appear on leaf and stem tissue, followed shortly by the production of pycnidia (Bier 1939). It has been reported that, throughout the growing season, when environmental conditions are suitable, conidia are produced, increasing the incidence and severity of both leaf spots and stem cankers (Ostry 1987; Waterman 1954). Differences in disease severity related to tissue age have been reported for Populus spp. (Foster et al. 2015) and Qin and LeBoldus (2014) hypothesized that only branch and stem tissues at a particular stage of development were susceptible to stem canker.

Although both facets of this disease have documented effects on yield, stem cankers are widely regarded as the greatest threat to commercial poplar plantations (Feau et al. 2010; Waterman 1954). Attempts to manage Septoria canker with cultural controls has proven ineffective at reducing the primary inoculum because the fungus is wind dispersed and typically found in nearby stands of native poplar trees (Gyenis et al. 2003; Ostry 1987). Chemical controls are too expensive due to the need

Corresponding author: J. M. LeBoldus;

E-mail: Jared.LeBoldus@science.oregonstate.edu

Accepted for publication 19 October 2016.

() 2017 The American Phytopathological Society for repeated applications during the growing season for the length of the plantations' rotation (Gyenis et al. 2003; Ostry 1987; Ostry and McNabb 1983). As a result, disease resistance is widely regarded as the best management option and this has emphasized breeding for stem canker resistance (Newcombe and Ostry 2001; Ostry 1987; Ostry and McNabb 1985). Several studies have indicated that there are significant differences among poplar genotypes in terms of resistance to both leaf spots and stem cankers (Dunnell et al. 2016; Krupinsky 1989; LeBoldus et al. 2010; Ostry and McNabb 1985; Weiland et al. 2003). However, it is unclear how selecting for stem canker resistance, a major criterion in hybrid poplar breeding programs in eastern and north-central North America, will affect resistance to leaf spot. Three separate studies have reported contradictory results with regards to correlations between leaf spot and stem canker resistance. Ward and Ostry (2005) reported a correlation between the necrotic area of inoculated leaf discs and the necrotic area of wound-inoculated stems in two experiments $(r=0.775$ and 0.606$)$. Herath et al. (2016) also reported a significant correlation (spearman rank correlation $=0.53 ; P<0.05$ ) when comparing the incidence of foliar infections with the abundance of cankers in plantations. In contrast, a field trial examining the inheritance of resistance in a threegeneration Populus trichocarpa $\times P$. deltoides pedigree noted no significant correlation $(r=0.22 ; P=0.68)$ between these two symptoms (Newcombe and Ostry 2001).

A correlation between leaf spot and stem canker resistance may suggest that there are similar mechanisms conferring resistance to both leaf spots and stem cankers. On the other hand, the lack of a correlation may indicate that there are different mechanisms of resistance in these two plant tissues. To our knowledge, no study has explicitly tested nonwounded trees under controlled conditions to examine this correlation. The overall objective of this study was to examine the relationship between resistance to leaf spot and stem canker disease. The specific objectives were to determine whether (i) there are differences in susceptibility associated with leaf age and (ii) there is a correlation between resistance to stem infection and resistance to leaf infection.

\section{Materials and Methods}

Pathogen propagation. Isolations of Sphaerulina musiva were made from individual branch cankers that were collected during the winter of 2011 from a commercial hybrid poplar plantation near Belle River, MN $\left(45.97^{\circ} \mathrm{N}, 95.19^{\circ} \mathrm{W}\right)$. Cankers were rinsed twice with sterile distilled water after soaking in a $5 \% \mathrm{NaClO}$ solution for $2 \mathrm{~min}$. The bark was removed from the stem and a 5-mm piece 
of wood was excised from the margin between healthy and necrotic tissue. These pieces were placed on petri plates with $\mathrm{KV}-8$ medium (180 ml of V-8 vegetable juice [Campbell Soup Company], $2 \mathrm{~g}$ of calcium carbonate, $20 \mathrm{~g}$ of agar, and $820 \mathrm{ml}$ of deionized water) (Stanosz and Stanosz 2002) amended with streptomycin sulfate (Amresco) at $100 \mathrm{mg} \mathrm{liter}^{-1}$ and chloramphenicol (Amresco) at $240 \mathrm{mg} \mathrm{liter}^{-1}$. Parafilm was wrapped around the petri plates and the cultures were incubated at room temperature (approximately $20^{\circ} \mathrm{C}$ ) under continuous light for 7 days. Subsequently, sporulating fungal colonies were transferred to new KV-8 petri plates. Species identity was confirmed by fungal morphology (Sivanesan 1990). In addition, these isolates were included as part of a larger multilocus genotyping study where species identity was confirmed (LeBoldus et al. 2015). Isolates were stored as mycelial plugs suspended in a $50 \%$ glycerol solution at $-80^{\circ} \mathrm{C}$ in 2-ml cryotubes.

Host propagation. Dormant branches from 17 hybrid poplar genotypes were collected from the Belle River archival plantation in Minnesota $\left(45.97^{\circ} \mathrm{N}, 95.19^{\circ} \mathrm{W}\right)$. Sixteen of these genotypes were $P$. deltoides $\times P$. nigra hybrids. A single $P$. nigra $\times P$. maximowiczii hybrid (NM6) was included as a susceptible control. Branches were cut into 10-cm lengths and planted in containers (Ray Leach SC10 Super Cone-tainers; Stuewe and Sons, Inc.), measuring $3.8 \mathrm{~cm}$ in diameter and $21 \mathrm{~cm}$ deep, filled with growing medium (SunGro Professional Mix number 8; SunGro Horticulture Ltd.) amended with $12 \mathrm{~g}$ of Osmocote fertilizer (15-9-12, N-P-K; 7.0\% $\mathrm{NH}_{3}-\mathrm{N}, 8.0 \% \mathrm{NO}_{3}-\mathrm{N}$, $9.0 \% \mathrm{P}_{2} \mathrm{O}_{5}, 12.0 \% \mathrm{~K}_{2} \mathrm{O}, 1.0 \% \mathrm{Mg}, 2.3 \% \mathrm{~S}, 0.02 \% \mathrm{~B}, 0.05 \% \mathrm{Cu}$, $0.45 \% \mathrm{Fe}, 0.23 \%$ chelated $\mathrm{Fe}, 0.06 \% \mathrm{Mn}, 0.02 \% \mathrm{Mo}$, and $0.05 \%$ Zn; Scotts Osmocote Plus; Scotts Company Ltd.) after soaking in water for $48 \mathrm{~h}$. After plants reached a height of $30 \mathrm{~cm}$, they were transplanted into 7.57-liter pots filled with growing medium amended with $38 \mathrm{~g}$ of Osmocote fertilizer (15-9-12, N-P-K) (DesRochers and Thomas 2003). Trees were grown in the greenhouse with an 18-h photoperiod supplemented with $600-\mathrm{W}$ high-pressure sodium lamps and a temperature regime of 20 and $16^{\circ} \mathrm{C}$ (day and night, respectively). Plants were watered as needed and slow-release fertilizer was supplemented on a weekly basis with 20-20-20 (N-P-K) liquid fertilizer (Scotts Peters Professional; Scotts Company Ltd.).

Inoculation. Cryotubes containing two isolates of $S$. musiva (MN14 and $\mathrm{MN}-5$ ) were poured onto KV-8 plates and grown under continuous light for 5 days. Each isolate was then subcultured onto 13 new KV-8 plates and grown for 7 days, at which point sporulation occurred. A spore suspension was prepared by adding approximately $5 \mathrm{ml}$ of distilled water to each plate and then dislodging the spores by rubbing the surface with a sterile inoculation loop. A separate spore suspension for each isolate was made and adjusted to a concentration of $1 \times 10^{6}$ conidia $\mathrm{ml}^{-1}$ (LeBoldus et al. 2010). Subsequently, equal volumes of each spore suspension were combined to create a bulk spore suspension.

Before conducting the inoculations, trees were removed from the greenhouse and their heights were measured. The leaves and stems were then inoculated with the bulk spore suspension by spraying them until run-off occurred. Approximately $15 \mathrm{ml}$ of spore suspension spray was used per tree. Inoculated trees were incubated at room temperature in black plastic bags for $48 \mathrm{~h}$. Control trees were treated in an identical manner, with the sole exception that sterile distilled water was used rather than the bulk spore suspension. Following removal from the bags, trees were returned to the greenhouse.

Experimental design. The experimental setting was a randomized complete block design with five blocks. Four of the blocks were inoculated and one block was a mock-inoculated control. Within each block, there were two trees of each of the 17 genotypes. The leaves and stem of both trees were inoculated. One of the two trees was used to measure leaf spot severity (treatment 1 ) and the second tree was used to measure stem canker severity (treatment 2). In total, 170 trees were used in the experiment (17 genotypes by two treatments by five blocks). Stems and leaves were harvested 21 days postinoculation. For treatment 1, five leaves were selected for analysis. Leaves were chosen by counting the total number of leaves at the time of inoculation and dividing this number by two, to determine the midleaf number. Subsequently, the midleaf and two leaves above and below were collected.
The collected leaves were numbered 1 to 5 , with the highest leaf collected on the stem (youngest) numbered 1 and the lowest leaf collected on the stem (oldest) numbered 5. This was done in order to have an equal number of leaves for all genotypes. In the case of a missing leaf, the adjacent leaf was collected. After collection, leaves were pressed in a plantpress, digitally scanned, and analyzed with Assess 2.0 software (Lamari 2008) to estimate the percent necrotic area of each leaf (leaf spot severity) by measuring the total necrotic area and dividing it by the total leaf area. For treatment 2, all stems were rated for stem canker severity by counting the cankers and dividing the count by the height (in centimeters) at the time of inoculation. The inoculation experiment was repeated.

Data analysis. A linear model using the mixed procedure in SAS 9.4 (SAS Institute) was used to analyze the effect of block, genotype, and leaf number nested within genotype (leaf[genotype]) on leaf spot severity. The initial model for leaf spot severity was $Y_{\mathrm{ijk}}=\mu+\beta_{\mathrm{i}}+G_{\mathrm{j}}+L_{\mathrm{k}}\left(G_{\mathrm{j}}\right)$ $+\varepsilon_{\mathrm{ijk}}$, where $Y_{\mathrm{ijk}}$ is the value in the $i$ th block for the $j$ th genotype for the $k$ th leaf number nested within the $j$ th genotype; $\mu$ is the overall mean; $\beta_{i}$ is the random effect of the $i$ th block, $\mathrm{i}=1$ to $4 ; G_{\mathrm{j}}$ is the fixed effect of the $j$ th genotype, $j=1$ to $17 ; L_{\mathrm{k}}\left(\mathrm{G}_{\mathrm{j}}\right)$ is the fixed effect of the $k$ th leaf number nested within the $j$ th genotype, $k=1$ to 5 ; and $\varepsilon_{\mathrm{ijk}}$ is the residual error.

A linear model was also used to analyze the effect of genotype on stem canker severity. The initial model for stem canker severity was $Y_{\mathrm{ij}}=\mu+\beta_{\mathrm{i}}+G_{\mathrm{j}}+\varepsilon_{\mathrm{ij}}$, where $Y_{\mathrm{ij}}$ is the value in the $i$ th block for the $j$ th genotype; $\mu$ is the overall mean; $\beta_{\mathrm{i}}$ is the random effect of the $i$ th block, $i=1$ to $4 ; \mathrm{G}_{\mathrm{j}}$ is the fixed effect of the $j$ th genotype, $j=1$ to 17 ; and $\varepsilon_{\mathrm{ijk}}$ is the residual error.

Statistical significance was assessed at $\alpha=0.05$. Initially, to determine whether the experiments could be analyzed together, homogeneity of variances was tested by comparing two models: one with and one without a repeated statement to model unequal variances between experiments. Next, a two-step process was used to test significance of both fixed and random effects. In the leaf spot severity model, the significance of the random effect of block was tested using the likelihood ratio $\chi^{2}$ test. Subsequently, an $F$ test was used to evaluate the significance of the fixed effects, genotype, and leaf(genotype). A similar procedure was used to pick the final model for stem canker severity. When necessary, unequal variances were modeled using the repeated statement in SAS.

Following model selection, the LSMEANS statement was used with a Tukey's correction for multiple comparisons to compare leaf spot severity among different leaf numbers. Next, genotype means for stem canker severity and leaf spot severity for each individual leaf number were estimated using best linear unbiased estimates (Littell et al. 2006). In addition, mean leaf spot severities for each leaf number across all genotypes were estimated. These values were used to conduct 11 correlations (Proc CORR) between each individual leaf number and stem canker severity for each experiment.

\section{Results}

Both cankers and leaf spots were similar to descriptions in the literature (Bier 1939; Thompson 1941). Cankers appeared between 2 and 3 weeks postinoculation. They were dark-brown expanding lesions that tended to be longer than they were wide. Leaf spots appeared circular and brown, sometimes with narrow yellow borders and lighter centers. Leaf spots frequently contained small black pycnidia. Stem cankers occasionally sporulated. Conidia produced in leaf spots matched the description of S. musiva (Bier 1939). No symptoms developed on control trees.

Due to unequal variances $(P<0.001)$, the two experiments were analyzed separately. However, for both leaf spot severity and stem canker severity, the final models were similar. The leaf spot severity models included block $\left(P_{\exp 1}=0.174 ; P_{\exp 2}=0.074\right)$, genotype $\left(P_{\exp 1}<0.001 ; P_{\exp 2}<0.001\right)$, and leaf(genotype $)\left(P_{\exp 1}=0.007 ;\right.$ $\left.P_{\exp 2}=0.060\right)($ Table 1$)$. The final stem canker severity models included block $\left(P_{\exp 1}=0.180 ; P_{\exp 2}=1.000\right)$ and genotype $\left(P_{\exp 1}=\right.$ $\left.0.006 ; P_{\exp 2}=0.014\right)($ Table 1$)$.

In general, there was significantly greater disease severity on younger compared with older leaves (leaf 1 versus leaf 5) when averaged across all genotypes. In the first experiment, leaf-by-leaf comparisons indicated that leaf 1 was significantly different than leaves 4 
and $5(P=0.022 ; P<0.001)$ and leaves 2 and 3 were significantly different than leaf $5(P=0.001 ; P=0.014)$. In experiment 2 , leaf 1 was significantly different than leaves 4 and $5(P=0.001 ; P<$
$0.001)$ and leaf 2 was significantly different than leaves 4 and 5 $(P=0.043 ; P=0.004)$. All other leaf numbers were not significantly different.

Table 1. Analysis of variance table for experiments (Exp) 1 and 2 with $P$ values for each parameter in the leaf spot severity and stem canker severity models of Populus hybrids inoculated with Sphaerulina musiva ${ }^{2}$

\begin{tabular}{|c|c|c|c|c|c|c|}
\hline \multirow[b]{2}{*}{ Parameter } & \multicolumn{3}{|c|}{ Leaf spot model } & \multicolumn{3}{|c|}{ Stem canker model } \\
\hline & df & $\operatorname{Exp} 1(P)$ & $\operatorname{Exp} 2(P)$ & df & $\operatorname{Exp} 1(P)$ & $\operatorname{Exp} 2(P)$ \\
\hline Block & 3 & 0.174 & 0.074 & 3 & 0.180 & 1.000 \\
\hline Genotype & 16 & $<0.001$ & $<0.001$ & 16 & 0.006 & 0.014 \\
\hline Leaf Number (genotype) & 68 & 0.007 & 0.060 & - & - & - \\
\hline Residual & 253 & - & - & 49 & - & - \\
\hline Total & 340 & - & - & 68 & - & - \\
\hline
\end{tabular}

${ }^{\mathrm{z}} P=P$ value and - represents no estimate.

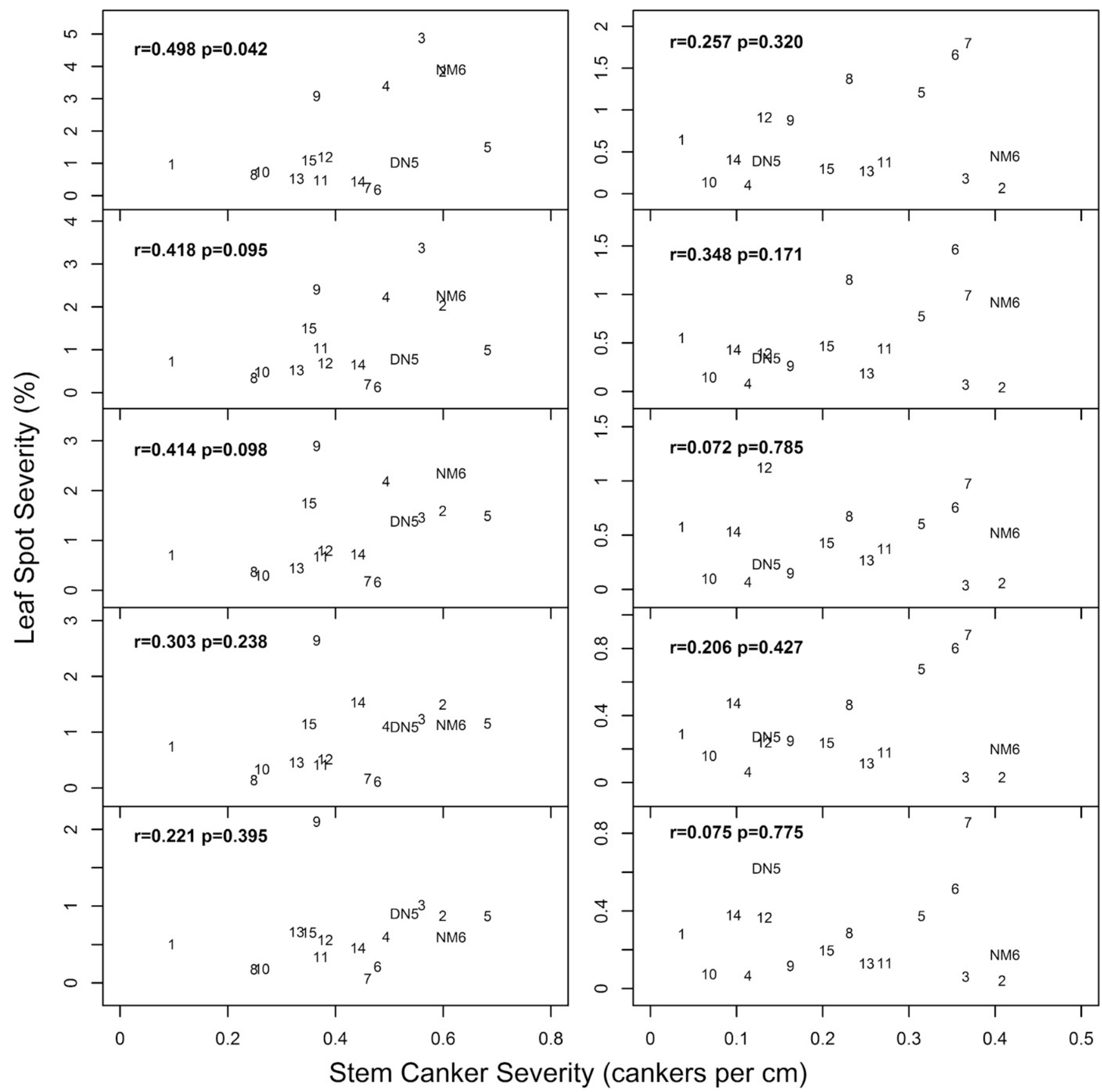

Fig. 1. Leaf spot severity (\%) of each Populus hybrid leaf (1-top to 5-bottom) inoculated with Sphaerulina musiva for each genotype correlated to stem canker severity (cankers per centimeter), with each label representing a different genotype; $r$ indicates the Pearson correlation coefficient and the $P$ value indicates the significance of the correlation (left column is experiment 1 and right column is experiment 2). 
In total, there was only 1 significant correlation of the 11 tested. The leaf spot severity of leaf 1 was correlated to stem canker severity in experiment 1 ( $r=0.498 ; P=0.042$; Fig. 1$)$. When leaf spot severity was averaged across all five leaves for each genotype, there was no correlation with stem canker severity $(r=0.452 ; P=0.068)$.

\section{Discussion}

The significant effect of leaf age in the two experiments is a common trend in plant pathology. This pattern of increasing resistance with tissue age is referred to as ontogenic resistance (Goto et al. 1961) and has been reported in other pathosystems (Asalf et al. 2014; Gadoury et al. 2003; Gusberti et al. 2013). Studies examining the mechanisms of ontogenic resistance have suggested that there are both physical barriers such as lenticel morphology and cuticle thickness (Ficke et al. 2002; Kennelly et al. 2005) as well as chemical mechanisms, including the accumulation of salicylic acid and pathogenesis-related proteins (Gusberti et al. 2013; Hugot et al. 1999; Kus et al. 2002). Regardless of the mechanism, leaf age may have important implications for sporulation and other epidemiological factors in this pathosystem.

Only one significant correlation between leaf spot severity and stem canker severity in $P$. deltoides $\times P$. nigra hybrids was reported when whole trees were inoculated under controlled conditions (Fig. 1). This lack of correlation is consistent with a previous report by Newcombe and Ostry (2001) that found that stem canker and leaf spot severity, rated on a 1-to-3 scale, were not correlated $(r=0.22)$ under field conditions. In contrast, both Ward and Ostry (2005) and Herath et al. (2016) reported significant correlations. The differences in terms of Populus spp. or hybrids tested, isolate populations that the trees were exposed to, disease parameters that were measured, and locations make it extremely difficult to determine the cause of the differing results between the two studies where significant correlations were detected (Herath et al. 2016; Ward and Ostry 2005) and the one with no correlation (Newcombe and Ostry 2001). It is also not straightforward to directly compare the results of an inoculation experiment conducted in controlled conditions with those of differing methodologies. In the case of Ward and Ostry (2005), part of the differences may be explained by the inoculation methods used: wounded (Ward and Ostry 2005) versus nonwounded, as described above. In the study by Herath et al. (2016), correlation was reported following the survey of established plantations observed over multiple years. This is the first study where nonwounded whole trees inoculated under controlled conditions were used to specifically evaluate the correlation between resistance to leaf spot and stem canker with a methodology shown to be predictive of resistance and susceptibility under field conditions (Qin et al. 2014).

Correlations between leaf spot and stem canker severity potentially have important implications for disease resistance breeding. Shifts in the frequency of virulence and avirulence alleles in pathogen populations, following the deployment of resistance genes, is well documented in agriculture (Hulbert et al. 1991; Johnson 1992; Kolmer 1992; Martens and Dyck 1989; McIntosh et al. 1983; Samborski

Table 2. Best linear unbiased estimates (BLUE), range of the data, and maximum-likelihood confidence limit (CL) for Sphaerulina musiva leaf spot severity (\%) and stem canker severity (cankers per centimeter) for each Populus hybrid genotype in experiments 1 and 2

\begin{tabular}{|c|c|c|c|c|c|c|c|c|}
\hline \multirow[b]{2}{*}{ Genotype } & \multicolumn{4}{|c|}{ Leaf spot severity } & \multicolumn{4}{|c|}{ Stem canker severity } \\
\hline & BLUE & Range & CL & Comparisons $^{\mathbf{z}}$ & BLUE & Range & CL & Comparisons $^{2}$ \\
\hline \multicolumn{9}{|c|}{ Experiment 1} \\
\hline 1 & 0.74 & $0.18-1.67$ & $0.22-1.25$ & abcdef & 0.10 & $0.05-0.20$ & $-0.10-0.29$ & $\mathrm{a}$ \\
\hline 2 & 1.97 & $0.13-7.30$ & $1.46-2.49$ & cdefghi & 0.60 & $0.41-0.86$ & $0.40-0.80$ & $\mathrm{~b}$ \\
\hline 3 & 2.40 & $0.41-9.13$ & $1.88-2.91$ & efghi & 0.56 & $0.32-0.81$ & $0.36-0.76$ & a \\
\hline 4 & 1.91 & $0.16-4.09$ & $1.36-2.46$ & bcdefghi & 0.49 & $0.32-0.67$ & $0.30-0.69$ & $\mathrm{a}$ \\
\hline 5 & 1.21 & $0.05-3.23$ & $0.69-1.72$ & abcdefgh & 0.68 & $0.44-0.79$ & $0.49-0.88$ & $\mathrm{~b}$ \\
\hline 6 & 0.17 & $0.06-0.43$ & $-0.35-0.68$ & abcde & 0.48 & $0.22-1.14$ & $0.28-0.67$ & a \\
\hline 7 & 0.17 & $0.01-0.40$ & $-0.35-0.69$ & abcde & 0.46 & $0.35-0.67$ & $0.26-0.66$ & a \\
\hline 8 & 0.34 & $0.03-1.15$ & $-0.18-0.86$ & abcde & 0.25 & $0.19-0.29$ & $0.05-0.45$ & $\mathrm{a}$ \\
\hline 9 & 2.63 & $0.15-8.05$ & $2.11-3.15$ & fghi & 0.37 & $0.28-0.52$ & $0.17-0.56$ & $\mathrm{a}$ \\
\hline 10 & 0.41 & $0.13-1.49$ & $-0.11-0.93$ & abcde & 0.26 & $0.03-0.42$ & $0.07-0.46$ & $\mathrm{a}$ \\
\hline 11 & 0.60 & $0.10-1.95$ & $0.08-1.11$ & abcde & 0.37 & $0.21-0.46$ & $0.18-0.57$ & $\mathrm{a}$ \\
\hline 12 & 0.75 & $0.17-2.03$ & $0.24-1.27$ & abcdef & 0.38 & $0.06-0.62$ & $0.18-0.58$ & $\mathrm{a}$ \\
\hline 13 & 0.53 & $0.12-1.36$ & $0.01-1.04$ & abcde & 0.33 & $0.17-0.47$ & $0.13-0.52$ & $\mathrm{a}$ \\
\hline 14 & 0.77 & $0.09-3.13$ & $0.25-1.28$ & abcdef & 0.44 & $0.31-0.57$ & $0.25-0.64$ & $\mathrm{a}$ \\
\hline 15 & 1.23 & $0.09-5.19$ & $0.72-1.75$ & abcdefgh & 0.35 & $0.12-0.61$ & $0.15-0.55$ & a \\
\hline DN5 & 1.04 & $0.07-2.36$ & $0.52-1.56$ & abcdefg & 0.53 & $0.25-0.77$ & $0.33-0.72$ & $\mathrm{a}$ \\
\hline NM6 & 2.05 & $0.18-9.68$ & $1.53-2.57$ & defghi & 0.61 & $0.43-0.77$ & $0.42-0.81$ & $\mathrm{~b}$ \\
\hline \multicolumn{9}{|c|}{ Experiment 2} \\
\hline 1 & 0.47 & $0.05-0.96$ & $0.27-0.68$ & abcdef & 0.04 & $0.02-0.07$ & $0.00-0.07$ & $\mathrm{a}$ \\
\hline 2 & 1.04 & $0.19-2.87$ & $0.84-1.25$ & defg & 0.35 & $0.28-0.39$ & $0.28-0.43$ & $\mathrm{~b}$ \\
\hline 3 & 1.10 & $0.05-3.97$ & $0.90-1.31$ & defg & 0.37 & $0.07-0.58$ & $-0.01-0.75$ & $a b$ \\
\hline 4 & 0.79 & $0.06-2.67$ & $0.59-1.00$ & cdefg & 0.23 & $0.12-0.34$ & $0.08-0.38$ & $\mathrm{ab}$ \\
\hline 5 & 0.33 & $0.01-1.93$ & $0.13-0.54$ & abcdef & 0.16 & $0.05-0.25$ & $0.02-0.31$ & $a b$ \\
\hline 6 & 0.05 & $0.01-0.11$ & $-0.15-0.26$ & $a b c$ & 0.41 & $0.16-0.85$ & $-0.08-0.90$ & $\mathrm{ab}$ \\
\hline 7 & 0.08 & $0.01-0.48$ & $-0.13-0.28$ & $a b c$ & 0.37 & $0.23-0.53$ & $0.15-0.58$ & $\mathrm{ab}$ \\
\hline 8 & 0.08 & $0.02-0.32$ & $-0.13-0.28$ & $a b c$ & 0.11 & $0.06-0.16$ & $0.03-0.20$ & $\mathrm{a}$ \\
\hline 9 & 0.73 & $0.12-2.18$ & $0.53-0.93$ & cdefg & 0.31 & $0.18-0.53$ & $0.07-0.56$ & $a b$ \\
\hline 10 & 0.12 & $0.02-0.45$ & $-0.08-0.33$ & abcd & 0.07 & $0.00-0.18$ & $-0.06-0.20$ & $\mathrm{a}$ \\
\hline 11 & 0.30 & $0.02-0.58$ & $0.10-0.51$ & abcdef & 0.27 & $0.01-0.46$ & $-0.05-0.60$ & $a b$ \\
\hline 12 & 0.61 & $0.09-3.14$ & $0.40-0.81$ & bcdefg & 0.13 & $0.06-0.21$ & $-0.06-0.32$ & $a b$ \\
\hline 13 & 0.20 & $0.02-0.49$ & $-0.01-0.40$ & abcde & 0.25 & $0.13-0.41$ & $0.06-0.44$ & $a b$ \\
\hline 14 & 0.45 & $0.09-0.97$ & $0.24-0.65$ & abcdef & 0.10 & $0.00-0.17$ & $-0.03-0.22$ & $\mathrm{a}$ \\
\hline 15 & 0.33 & $0.05-1.54$ & $0.12-0.53$ & abcdef & 0.20 & $0.13-0.31$ & $0.09-0.32$ & $a b$ \\
\hline DN5 & 0.37 & $0.03-1.41$ & $0.17-0.58$ & abcdef & 0.13 & $0.05-0.22$ & $0.02-0.24$ & $\mathrm{a}$ \\
\hline NM6 & 0.45 & $0.09-3.00$ & $0.25-0.66$ & abcdef & 0.41 & $0.16-0.65$ & $0.05-0.78$ & $\mathrm{ab}$ \\
\hline
\end{tabular}

${ }^{z}$ Comparisons were calculated using Tukey's honestly significant differences, and the letters indicate which genotypes are significantly different. 
1985). In the S. musiva-Populus pathosystem, the majority of the inoculum is produced by leaf spots, either as ascospores in the spring or conidia during the growing season (Bier 1939; Ostry 1987; Thompson 1941). As a result, understanding how selection and deployment of genotypes with resistance to stem canker may affect the pathogen population producing that inoculum is extremely important. For example, if a genotype is equally resistant to leaf spot and stem canker, then selecting resistance to stem canker will also select for resistance to leaf spot. This may result in a strong selection pressure on the pathogen population, potentially affecting the durability of stem canker resistance over the course of a rotation. On the other hand, the absence of a correlation between stem canker and leaf spot resistance suggests that this selection pressure may not exist, and that the durability of stem canker resistance may be independent of leaf spot resistance. An example of this can be seen in populations of the coevolved host $P$. deltoides, which are susceptible to leaf spot but not stem canker (Newcombe 1998; Newcombe and Ostry 2001; Ostry 1987). The absence of a correlation also suggests that there may be different mechanisms conferring resistance in the two different plant tissues, with potentially important consequences for breeding programs. However, it is important to note that this would need to be specifically tested to confirm this hypothesis.

In this study, trees were inoculated with a bulked spore suspension rather than individual isolates in order to simulate natural infection. Although this approach was able to detect significant differences among genotypes in terms of their relative levels of resistance to leaf spot and stem canker (Table 2, Figs. 2 and 3), no information on specific genotype-isolate interactions was collected. Most studies indicate that genotypic differences explain the majority of variation in this system rather than isolate or genotype-isolate interaction effects (Dunnell et al. 2016; Krupinsky 1989; LeBoldus et al. 2008; Weiland et al. 2003). However, the possibility exists that differences among isolates may play an important role in the epidemiology of this disease. For example, it is possible that some isolates sporulate more profusely than others. Alternatively, there may be differences in the ability of isolates to sporulate on woody tissue versus leaf tissue. Further evidence that tissue-specific responses may play an important epidemiological role in this pathosystem is illustrated by the significant leaf (genotype) effect (Table 1) and the differences in disease severity among leaf ages.

There are other aspects of pathogen biology that should be taken into account when deploying resistant genotypes. For example, when considering the durability of resistance, what is the frequency and extent of sexual reproduction in the pathogen population? There is evidence that $S$. musiva reproduces sexually (Feau et al. 2005; Sakalidis et al. 2016). Using population genetics to identify the source of introduction of S. musiva to British Columbia, Sakalidis et al. (2016) found evidence of sexual recombination as well as the presence of both mating types in the North American population of $S$. musiva. This ability to generate novel genetic diversity may be more important in terms of the durability of resistance to stem canker than the lack of a correlation between leaf spot and stem canker severity. This is perhaps illustrated by the loss of resistance to stem canker in a plantation of the genotype NM6, previously considered resistant to the disease (Weiland et al. 2003). Although the cause was not determined, one possible explanation is recombination in the pathogen

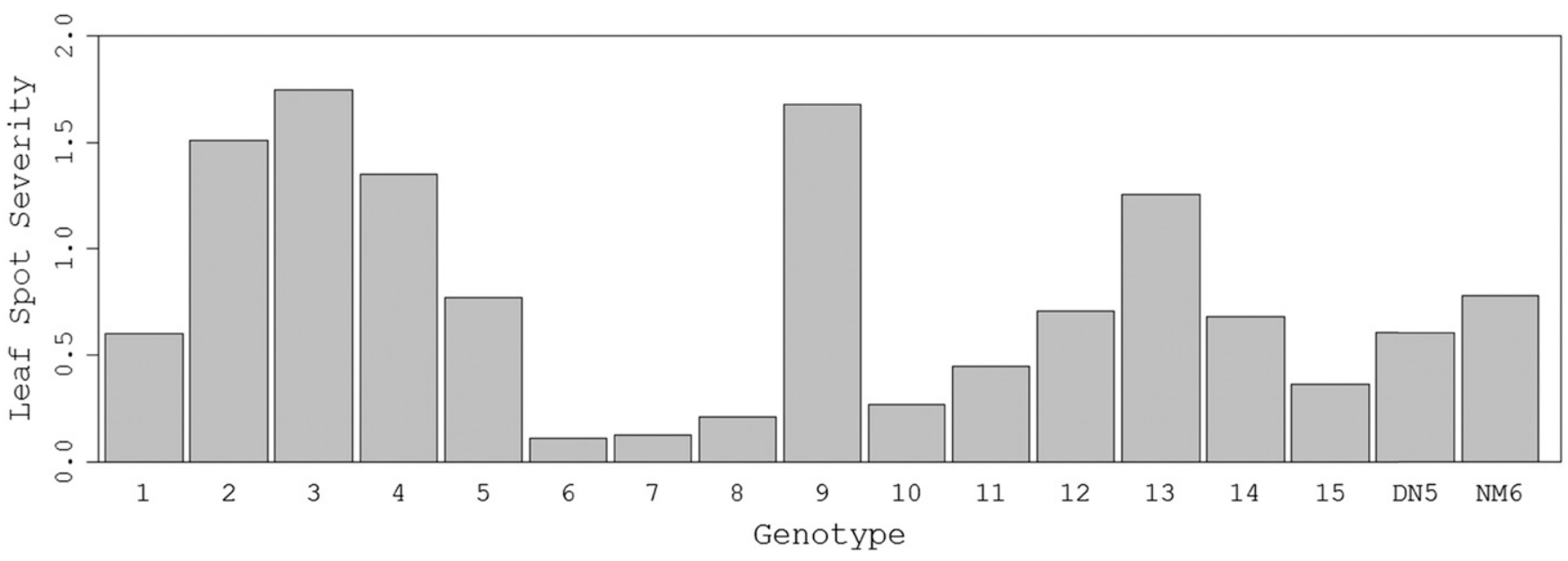

Fig. 2. Mean stem canker severity (cankers per centimeter) for each Populus hybrid genotype inoculated with Sphaerulina musiva averaged across both experiments.

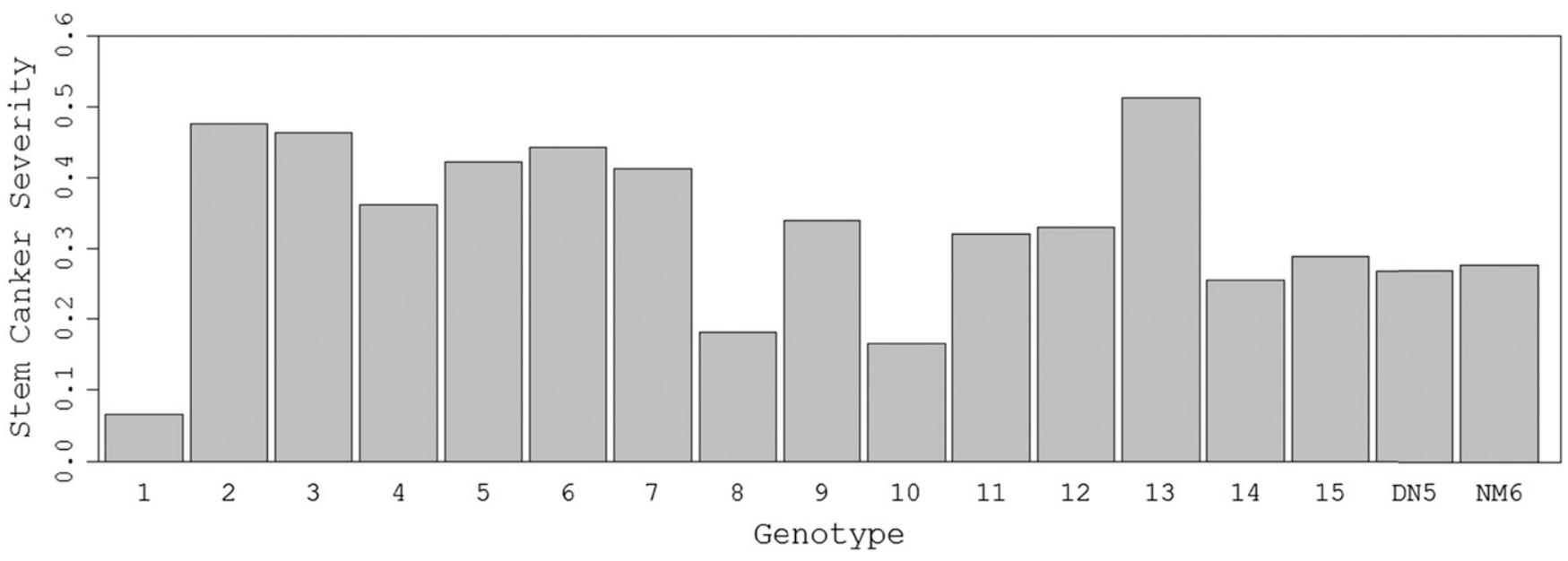

Fig. 3. Mean leaf spot severity (percent) of Sphaerulina musiva inoculated leaves for each Populus hybrid averaged across both experiments. 
population leading to changes in virulence. Another potential consideration is the polycyclic nature of the disease. In these experiments, the inoculation of leaves and stems occurred once, followed by disease severity ratings 3 weeks later. This is unlikely to be the case in a plantation setting where multiple cycles of infection and sporulation may occur in one growing season or across multiple years (Ostry 1987; Waterman 1954).

In conclusion, the lack of a consistent correlation may have implications for disease management and deployment of resistant genotypes. Stem canker resistance may be more durable as a result of the pathogen's ability to infect the leaves regardless of resistance to stem infection; however, sexual reproduction within the pathogen population may be an important factor in generating novel genetic diversity affecting the durability of resistance. This study also provides evidence that leaf age plays an important role in disease resistance to $S$. musiva. Overall, this study is an important first step in understanding the interaction between two different facets of this important pathogen.

\section{Acknowledgments}

This study was supported by the United States Department of Agriculture National Institute of Food and Agriculture USDA-NIFA-RIPM 2012-34103-19771 grant to J. M. LeBoldus. Work on collection and establishment of field tests was supported by the United State Department of Energy, Sun Grant Initiative Regional Biomass Feedstock Partnership through a subcontract from South Dakota State University. A Graduate Research Assistantship was provided to K. L. Dunnell from the Botany and Plant Pathology department at Oregon State University. We thank B. McMahon for providing plant material and K. Mettler for technical assistance.

\section{Literature Cited}

Asalf, B., Gadoury, D. M., Tronsmo, A. M., Seem, R. C., Dobson, A., Peres, N. A., and Stensvand, A. 2014. Ontogenic resistance of leaves and fruit, and how leaf folding influences the distribution of powdery mildew on strawberry plants colonized by Podosphaera aphanis. Phytopathology 104:954-963.

Bier, J. E. 1939. Septoria canker of introduced and native hybrid poplars. Can. J. Res. 17c:195-204.

Bisoffi, S., and Gullberg, U. 1996. Poplar breeding and selection strategies. Pages 139-155 in: Biology of Populus and Its Implications for Management and Conservation. R. F. Stettler, H. D. Bradshaw, Jr., P. E. Heilman, and T. M. Hinckley, eds. NRC Research Press, National Research Council of Canada, Ottawa, ON Canada

DesRochers, A., and Thomas, B. R. 2003. A comparison of pre-planting treatments on hardwood cuttings of four hybrid poplar clones. New For. 26:17-32.

Dickmann, D. I. 2001. An overview of the genus Populus. Pages 1-42 in: Poplar Culture in North America. Part A, Chapter 1. D. I. Dickmann, J. G. Isebrands, J. E. Eckenwalder, and J. Richardson, eds. NRC Research Press, National Research Council of Canada, Ottawa, ON Canada.

Dunnell, K. L., Berguson, B., McMahon, B., and LeBoldus, J. M. 2016. Variation in resistance of Populus nigra to Sphaerulina musiva in the north-central United States. Plant Dis. 100:287-291.

Feau, N., Hamelin, R. C., Vandecasteele, C., Stanosz, G. R., and Bernier, L. 2005. Genetic structure of Mycosphaerella populorum (anamorph Septoria musiva) populations in north-central and northeastern North America. Phytopathology 95:608-616.

Feau, N., Mottet, M. J., Périnet, P., Hamelin, R. C., and Bernier, L. 2010. Recent advances related to poplar leaf spot and canker caused by Septoria musiva. Can. J. Plant Pathol. 32:122-134.

Ficke, A., Gadoury, D. M., and Seem, R. C. 2002. Ontogenic resistance and plant disease management: A case study of grape powdery mildew. Phytopathology 92:671-675.

Foster, A. J., Pelletier, G., Tanguay, P., and Séguin, A. 2015. Transcriptome analysis of poplar during leaf spot infection with Sphaerulina spp. PLoS One 10:e0138162.

Gadoury, D. M., Seem, R. C., Ficke, A., and Wilcox, W. F. 2003. Ontogenic resistance to powdery mildew in grape berries. Phytopathology 93:547-555.

Goto, K., Hirano, K., and Ohata, K. 1961. Susceptibility of leaf of rice to blast in relation to leaf age and position. 1. Variation of susceptibility among different leaf positions and grades of emergence of the top leaf. Spec. Bull. Okayama Pref. Agric. Exp. Stn. 58:77-88.

Gusberti, M., Gessler, C., and Broggini, G. A. L. 2013. RNA-seq analysis reveals candidate genes for ontogenic resistance in Malus-Venturia pathosystem. PLoS One 8:e78457.

Gyenis, L., Anderson, N. A., and Ostry, M. E. 2003. Biological control of Septoria leaf spot disease of hybrid poplar in the field. Plant Dis. 87:809-813.

Herath, P., Beauseigle, S., Dhillon, B., Ojeda, D. I., Bilodeau, G., Isabel, N., GrosLouis, M. C., Kope, H., Zeglen, S., Hamelin, R. C., and Feau, N. 2016.
Anthropogenic signature in the incidence and distribution of an emerging pathogen of poplars. Biol. Invasions 18:1147-1161.

Hugot, K., Aimé, S., Concord, S., Poupet, A., and Galiana, E. 1999. Developmental regulated mechanisms affect the ability of a fungal pathogen to infect and colonize tobacco leaves. Plant J. 20:163-170.

Hulbert, S. H., Lyons, P. C., and Bennetzen, J. L. 1991. Reactions of maize lines carrying $R p$ resistance genes to isolates of the common rust pathogen, Puccinia sorghi. Plant Dis. 75:1130-1133.

Johnson, R. 1992. Reflections of a plant pathologist on breeding for disease resistance, with emphasis on yellow rust and eyespot of wheat. Plant Pathol. 41:239-254.

Kennelly, M. M., Gadoury, D. M., Wilcox, W. F., Magarey, P. A., and Seem, R. C. 2005. Seasonal development of ontogenic resistance to downy mildew in grape berries and rachises. Phytopathology 95:1445-1452.

Kolmer, J. A. 1992. Diversity of virulence phenotypes and effect of host sampling between and within populations of Puccinia recondita f. sp. tritici in Canada Plant Dis. 76:618-621.

Krupinsky, J. M. 1989. Variability in Septoria musiva in aggressiveness Phytopathology 79:413-416.

Kus, J. V., Zaton, K., Sarkan, R., and Cameron, R. K. 2002. Age-related resistance in Arabidopsis is a developmentally regulated defense response to Pseudomonas syringae. Plant Cell 14:479-490.

Lamari, L. 2008. Assess 2.0: Image Analysis Software for Plant Disease Quantification. American Phytopathological Society, St. Paul, MN. doi 10.1094/assess 2.0

LeBoldus, J. M., Blenis, P. V., and Thomas, B. R. 2008. Clone by isolate interaction in the hybrid poplar-Septoria musiva pathosystem. Can. J. For. Res. 38:1888-1896.

LeBoldus, J. M., Blenis, P. V., and Thomas, B. R. 2010. A method to induce stem cankers by inoculating nonwounded Populus clones with Septoria musiva spore suspensions. Plant Dis. 94:1238-1242.

Leboldus, J. M., Kinzer, K., Richards, J., Ya, Z., Yan, C., Friesen, T. L., and Brueggeman, R. 2015. Genotype-by-sequencing of the plant-pathogenic fungi Pyrenophora teres and Sphaerulina musiva utilizing Ion Torrent sequence technology. Mol. Plant Pathol. 16:623-632.

Littell, R. C., Milliken, G. A., Stroup, W. W., Wolfinger, R. D., and Schabenberger, O. 2006. SAS for Mixed Models, 2nd ed. SAS Institute Inc. Cary, N.C.

Luley, C. J., and McNabb, H. S. 1989. Ascospore production, release, germination and infection of Populus by Mycosphaerella populorum. Phytopathology 79: 1013-1018

Martens, J. W., and Dyck, P. L. 1989. Genetics of resistance to rust in cereals from a Canadian perspective. Can. J. Plant Pathol. 11:78-85.

McIntosh, R. A., Luig, N. H., Milne, D. L., and Cusick, J. 1983. Vulnerability of triticales to wheat stem rust. Can. J. Plant Pathol. 5:61-69.

Newcombe, G. 1998. A review of exapted resistance to diseases of Populus. Eur. J. For. Pathol. 28:209-216.

Newcombe, G., and Ostry, M. 2001. Recessive resistance to Septoria stem canker of hybrid poplar. Phytopathology 91:1081-1084.

Ostry, M. E. 1987. Biology of Septoria musiva and Marssonina brunnea in hybrid Populus plantations and control of Septoria canker in nurseries. Eur. J. For. Pathol. 17:158-165.

Ostry, M. E., and McNabb, H. S., Jr. 1983. Diseases of intensively cultured hybrid poplars: A summary of recent research in the north central region. U. S. Dep. Agric. For. Serv. Gen. Tech. Rep. NC-91. Washington, DC.

Ostry, M. E., and McNabb, H. S., Jr. 1985. Susceptibility of Populus species and hybrids to disease in the north central United States. Plant Dis. 69:755-757.

Qin, R., and LeBoldus, J. M. 2014. The infection biology of Sphaerulina musiva: Clues to understanding a forest pathogen. PLoS One 9:e103477.

Qin, R., Stanosz, G. R., and LeBoldus, J. M. 2014. A nonwounding greenhouse screening protocol for prediction of field resistance of hybrid poplar to Septoria canker. Plant Dis. 98:1106-1111.

Sakalidis, M. L., Feau, N., Dhillon, B., and Hamelin, R. C. 2016. Genetic pattern reveal historical and contemporary dispersal of a tree pathogen. Biol. Invasions 18:1781-1799.

Samborski, D. J. 1985. Wheat leaf rust. Pages 39-59 in: Cereal Rusts, Vol. II. A. P Roelfs and W. R. Bushnell, eds. Academic Press, New York, London.

Sivanesan, A. 1990. Mycosphaerella populorum. CMI description of pathogenic fungi and bacteria, no 988. Mycopathologia 109:57-58.

Stanosz, J. C., and Stanosz, G. R. 2002. A medium to enhance identification of Septoria musiva from poplar cankers. For. Pathol. 32:145-152.

Thompson, G. E. 1941. Leaf-spot diseases of poplars caused by Septoria musiva and $S$. populicola. Phytopathology 31:241-254.

Ward, K. T., and Ostry, M. E. 2005. Variation in Septoria musiva and implications for disease resistance screening of poplars. Plant Dis. 89:1077-1082.

Waterman, A. M. 1954. Septoria canker of poplars in the United States. U.S. Dep. Agric. Circ. No. 947:1-22.

Weiland, J. E., Stanosz, J. C., and Stanosz, G. R. 2003. Prediction of long-term canker disease damage from the responses of juvenile poplar clones to inoculation with Septoria musiva. Plant Dis. 87:1507-1514 